New Zealand journal of industrial relations, 1991, 16, 249-254

\title{
People with disabilities in the labour market: an introduction
}

\author{
Alison Riseborough*
}

\section{Defining disability}

In order to understand the position of people with disabilities in the labour market it is first necessary to have some understanding about disability itself. This, however, is not a straight forward matter. The nature of disability is currently the subject of considerable debate in New Zealand and overseas (Johns, 1991). Traditional views which focus on an individual's medical condition, or see people with disabilities as victims of tragic circumstance in need of charitable aid, are being challenged by people with disabilities on a number of different grounds. New messages are being promoted about disability which attempt to re-define the position of people with disabilities in society.

The medical view of disability is apparent in the 2 definitions most commonly used in New Zealand. The World Health Organisation's 3-part definition (or various adaptations of it), has gained widespread usage in this country. According to the World Health Organisation:

an impairment is an anatomic or functional abnormality which may result in a disability; a disability is a loss or reduction in functional ability which results from an impairment; and a handicap is the disadvantage caused by a disability. Handicap represents the social and environmental consequences to the individual stemming from the presence on an impairment or disability.

The International Labour Organisation's definition is frequently used in discussions of the labour market status of people with disabilities. ILO Convention 159 defines a person with a disability as any person "whose prospects of securing, retaining and advancing in employment are reduced as a consequence of a recognised physical or mental impairment".

Both of these definitions concentrate on impairment of physical or mental function. The implicit assumption is that the position of people with disabilities in society and the labour market is primarily determined by the impaired function of some part of their body or mind. This focus on impairment is challenged by many people with disabilities on the grounds that it ignores their essential humanity. Evidence of this is the campaign over the last decade to have the terms "disabled people" and "the disabled" replaced by the phrase "people with disabilities". People with disabilities want to be recognized as worthwhile individuals who may have one or more of a wide variety of disabilities - some of which are obvious and some invisible, some minor some major, some permanent others temporary, some stable others progressive or episodic, some present at birth others occurring later in life and so on. The experience of disability varies considerably from individual to individual.

Even more important, people with disabilities want to be recognized as having abilities as well as disabilities. The often repeated catch cry is that "people with disabilities are people first and have disabilities second". Another slogan "focus on 
ability", which has appeared on a number of recent posters promoting employment opportunities for people with disabilities, is aimed at delivering this message in the labour market. Every member of society has abilities as well as things they are less able at doing. Like everybody else, people with disabilities in the labour market want to be considered on their individual merits for jobs and promotion, and not be discriminated against by employers and managers because of their disability.

Significantly, this view of disability focussing on the individual is now being questioned by some who consider it does not adequately account for the experience of people with disabilities in society in general and the labour market in particular. It is argued that while the experience of disability may vary considerably from person to person, people with disabilities share many common experiences as a result of the way the rest of society relates to them. People with disabilities as a group face indirect or systemic discrimination in a society that is "designed around and for non-disabled people". Society does not value their differences or cater for their needs. They are expected to try to adjust and "cope in spite of their disabilities", or to accept a position outside the mainstream of society.

The past 5 years have seen the advent of new messages aimed at challenging the systemic or societal discrimination experienced by people with disabilities. Recognizing parallels with other groups subject to discrimination, some people with disabilities have begun promoting the concept of "disability pride". This concept has a dual message. People with disabilities are encouraged to value themselves for who they are, not to try to conceal or minimize their disability. Society is asked to accept people including their disabilities not in spite of their disabilities. These new concepts are summed up by the slogan on a recent poster promoting equal employment opportunities in the public sector - "Who we are is ok, what happens to us is not".

The concept of "disability pride" with its corollary that people with disabilities want control over their own destinies, is still a somewhat radical notion even among people with disabilities, let alone the rest of the community. The debate on the nature of disability and the position of people with disabilities in society looks set to continue for some time to come.

\section{Labour market status of people with disabilities - existing evidence}

Efforts by people with disabilities to re-define themselves and their position in society are reflected in a growing interest in studying their circumstances in the labour market. Employment is one of the key factors determining a person's status in New Zealand society. Correspondingly, the status a person has in the the labour market provides an indicator of their position in society.

Examination of the readily available literature reveals that there is very little documented evidence on the labour market status of people with disabilities in New Zealand. Issues concerning people with disabilities have been overlooked in most studies of employment, unemployment and industrial relations in this country, and there has been relatively little research or analysis specifically on this group. The few studies which have been carried out show that many people with disabilities experience low status and discrimination in the labour market.

\section{Labour force participation and rates of unemployment}

In late 1991, a working party was set up by the Government to develop an integrated policy to facilitate the employment and training of people with disabilities. The Working Party on Employment and Training Policies for People with Disabilities 
endeavoured to establish a picture of the labour market status of people with disabilities on which to base its analysis of existing policies and recommendations for future policy development. On discovering the serious lack of information in this area, the Working Party commissioned BERL to pull together and analyse what statistical data was available and to formulate estimates on the labour force participation and employment status of people with disabilities.

Extrapolating from earlier local surveys and comparisons with overseas data, BERL estimated that in 1990 there were 117,500 males and 111,300 females with disabilities aged between 15 and 59 in New Zealand. This constituted 11.8 percent of all males and 11.1 percent of all females aged between 15 and 59 . The rate of disability was 11.4 percent across both sexes (Stroombergen, 1991, p.2).

People with disabilities were found to have a "high desire for work", with estimated labour force participation rates of 89.5 percent for males and 73.8 percent for females with disabilities (Working Party on Employment and Training Policies for People with Disabilities, 1991, p.1). The Working Party concluded from this that:

the existence of such high labour force participation rates, despite our comprehensive social security system, shows that people with disabilities share other New Zealanders' conviction that work is not only a means of economic survival, but also an important source of social status and meaningful life experience (Working Party, 1991, p. 17).

BERL's estimates also showed that, despite their high desire to work, people with disabilities are much more likely to experience unemployment than the working age population as a whole. The proportion of people with disabilities aged 15-59 who were unemployed in 1990 was 21.9 percent, compared to a national unemployment rate of 7.3 percent in March 1990 (Household Labour Force Survey). Women with disabilities were more likely to be unemployed than men with disabilities. 37.6 percent of women were estimated to be unemployed compared to an unemployment rate of 9.6 percent for men with disabilities (Stroombergen et al., 1991, p. 5).

These unemployment rates refer to those people with disabilities in the labour force actively seeking work. (The labour force is defined by BERL as those working one or more hours a week in paid employment plus unemployed people actively seeking work or about to start a job). BERL tentativeily estimated that when those unable to work, those able but not actively seeking work, and those in training or education, were added to those actively seeking work, about 40 percent of people with disabilities would be found to be "not working" (Stroombergen et al.,1991, p. 22).

\section{Factors contributing to high unemployment among people with disabilities}

The current high level of unemployment in New Zealand has affected all sectors of the community. People with disabilities are no exception. However, given that people with disabilities have an unemployment rate 3 times greater than the labour force as a whole, there clearly must be additional factors impacting on their ability to gain employment.

It is commonly assumed that the primary reason people with disabilities experience difficulty in gaining employment is that their disability limits their ability to perform necessary tasks. However, most people with disabilities are realistic about what they can and cannot do, and seek employment which lies within their capabilities. As the Working Party on Employment and Training Policies for People with Disabilities commented: 
... for many people with disabilities, the capacity to make a useful economic contribution will significantly outweigh any incapacities.

The primary barrier to securing, retaining and advancing in employment which many people with disabilities face, are the widely held stereotypes about people with disabilities, which hinder employers and others from looking beyond the disability to the abilities, and lead to discriminatory practices in appointing and promoting employees (1991, p.22).

There is considerable anecdotal evidence from people with disabilities, scattered throughout many documents, that they experience active discrimination from some employers when seeking work, even when they have the necessary skills for a job. Employers have tendencies both to overestimate the skills, physical and mental abilities required for jobs they offer and to underestimate the capabilities of people with disabilities who apply for these jobs.

Studies have confirmed what people with disabilities have long suspected, that the level of discrimination experienced varies considerably between different sub-groups of the disability population. A survey of private sector employers carried out by Philippa Bascand in 1986 found that the attitudes of employers to hiring someone with a disability vary depending on the nature or cause of disability. For example, the survey found employers were often reluctant to employ people with visible disabilities in positions dealing with the public because of concern about their company's image. Employers also expressed strong reluctance to employ anyone with a history of mental illness (Bascand, 1987).

Similar findings were noted in a survey of employers in the Hamilton area conducted by the New Zealand Employment Service in 1989. The majority of employers indicated a willingness to consider employing a person with a minor sight impairment, hearing impairment or epilepsy. Few employers were prepared to employ a person "with little or no sight", or someone who was "totally deaf", had a history of alcohol or drug abuse, used a wheelchair, or had a moderate intellectual disability. Reasons cited for not considering such individuals varied according to disability but included the belief that a person with that disability could not do the kind of work offered by the company, concerns about safety, and about lack of physical access to their building (Raethel, 1989).

A further factor contributing to the high unemployment of people with disabilities is their tendency to have lower educational achievement and fewer qualifications than average, which limits their prospects for employment. Lower parental expectations of children with disabilities (Neale, 1984), lack of physical access to educational facilities, and lack of resources to meet the specific learning needs of some children with disabilities have been identified as some of the factors limiting the educational opportunities of young people with disabilities.

A recent survey by the Disabled Persons Assembly of its members, and of participants in sheltered workshops, found that a lack of suitable and affordable transport is considered by many people with disabilities to be a major barrier to "achieving full participation in the community and labour market" (Disabled Persons Assembly, 1990). Lack of physical access and appropriate facilities in many workplaces were identified as being barriers to employment for some people with physical disabilities.

\section{People with disabilities in employment}

The high levels of unemployment and the barriers they face in gaining employment are issues of serious concern for people with disabilities, their support groups and policy makers. However, to gain a complete picture of people with disabilities in the labour market it is necessary to consider the position of the majority of people with disabilities 
in the labour market who do find their way into jobs. Again there is a dearth of information in this area.

Two studies which have been published focused on the barriers to equal employment opportunities in the public service. The Review of the Employment of Disabled Persons in the Public Service conducted by Joan Stone in 1986 found that people with disabilities were discriminated against in recruitment, selection, training, promotion, work conditions and expectation of fulfilling duties (Stone, 1986). Similarly, a nationwide survey of public servants in 1989 found that 13 percent of respondents considered they had experienced discrimination. The most common form of discrimination was other people's attitudes, but some felt they had limited opportunities for promotion or had been discriminated against when applying for jobs or seeking transfers (Gray and Burns, 1989).

It is reasonable to assume that similar barriers to career advancement for people with disabilities also occur in the private sector. The likely consequence is that when people with disabilities are in employment they are concentrated in lower graded and lower paid positions. Further research is needed to confirm this and to throw light on many other aspects of the relative status of people with disabilities in employment.

\section{A final comment}

Many people with disabilities have come to consider that the greatest challenge they face is not their disability (however that may be defined), but the way the rest of society relates to them. When it comes to participation in the labour market, the attitudes and behaviour of employers, managers and co-workers play an obvious role in influencing the employment prospects of people with disabilities. Less obvious are the systemic barriers posed by job descriptions, work practices, buildings and transport systems designed around and for non-disabled people. A key to overcoming these barriers is the development of greater understanding and appreciation of both the capabilities and needs of people with disabilities.

This paper has endeavoured to add to that understanding: pulling together what information is available to draw a general picture of the position of people with disabilities in the labour market. What is apparent is that there are currently large holes in the picture and a lack of detail. There is clearly a need for further study, from many different perspectives, to fill in some of those holes and encourage greater understanding.

\section{References}

Bascand P.J. (1987) Disabled people in employment: a survey of employers attitudes. Wellington, Rehabilitation League NZ Inc.

Disabled Persons Assembly (1990) Report on results of consumer consultation process to assist in the development of the Vocational Opportunities Support Programme. Wellington.

Gray A. and Burns J.A. (1989) A survey for people with disabilities in the Public Service. Wellington, EEO Unit, State Services Commission.

Johns K. (1991) Employment and training policies for people with disabilities: a literature review. Wellington, Department of Labour.

Neale, J. (1984) Where next? A survey of the parents of disabled form four students. Wellington, Further Education Group.

Raethel M. (1989) Employer survey on people with disabilities. Hamilton, Employment Service, Department of Labour. 
State Services Commission (1990) The invisible minority: a report of the Policy Development Working Group on the Employment of People with Disabilities. Wellington.

Stone J. (1986) Review of employment of disabled persons in the Public Service. Wellington, State Services Commission.

Stroombergen, A.H., Miller J. and Jensen B. (1991) Estimates of the labour force and employment status of people with disabilities 1990. Wellington, Department of Labour.

Working Party on Employment and Training Policies for People with Disabilities (1991) Developing an integrated policy to facilitate employment and training of people with disabilities: a report to the Minister of Employment. Wellington. 